\title{
An Investigation into Some Lexical Ambiguities in Algebra: South African Experience
}

\author{
Prof Emmanuel O. Adu PhD \\ Faculty of Education, University of Fort Hare, South Africa \\ eadu@ufh.ac.za \\ Mrs Olabisi Olaoye \\ Faculty of Education, University of Fort Hare South Africa \\ olabisiolaoye@yahoo.com
}

\section{Doi:10.5901/mjss.2014.v5n20p1243}

\section{Abstract}

\begin{abstract}
Many scholars in the field of mathematics education have written a lot about algebra. They commented that the simple and consistent rules for using abstract numbers and the shorthand symbols for mathematical verbs and operators in algebra evolved very slowly. Therefore, this study has revealed some of the lexical ambiguities in algebra aspect of mathematics. These ambiguities include among others; word problem in algebra, fallacies and hitches of word problem in algebra, linguistic complexity in algebra, proficiency in language of instruction problem just to mention but a few. The model for conceptualizing algebraic activity was no left behind. The study however recommends among others that there should be a paradigm shift in the method of teaching algebra and mathematics as a subject so as to enhance students' academic performance. The choice of methodology especially the student-centred methods (contemporary methods of teaching) are very pertinent at this stage since researches have shown that many students have phobia for mathematics. Hence, there is need for teachers to update their knowledge about the problem solving skills that can be used as a panacea to mathematics phobia and algebra ambiguities.
\end{abstract}

Keywords: Lexical ambiguities, Algebra, Mathematics, Language, South Africa experience

\section{Introduction}

In the recent years, the need to maintain a globally competitive workforce and the trend of interest in science and technology has made researchers to place much emphasis on mathematics because all other science related subjects are expressed, formulated and communicated through mathematics. Also, mathematics is important even in shaping how individuals deal with the various aspects of private, social and civil life. (Bouchey and Harter, 2005). Despite the importance of mathematics it is quiet unfortunate that many nations are grappling with students' underachievement in mathematics. This has become a major preoccupation of policy makers, think tanks, mathematics educators and all stakeholders involved in a bid to proffer a lasting solution to the problem. In the past 30 years, a plethora of research studies have shown that the major difficulties learners encounter in mathematics is in the area of language, they pointed out the relationship between language and mathematics teaching and learning. (Barwell. 2005).

It has even been suggested that the difficulties children encounter in mathematics might be a reflection of deficient linguistic processes as opposed to deficits in quantitative processes (Lefebvre et.al; 2010). Again, studies have revealed that children tend to have difficulty with language-based mathematical tasks (e.g. number fact, word problems) than with tasks that have fewer language demands.(Morgan, 2007). The supposition of all these findings is that there is an inextricable link between linguistic skills and mathematical performance, pointing out the interrelationship between language and mathematics that mathematics is not 'language free' because despite its abstract nature, use of symbols and graphical representation, it is still expressed through language.

Daniel and James (2003) state that research efforts should be directed towards studies that would explore the relationship among selected aspects of mathematics performance and various linguistic skills. Again, one of the challenges encountered by mathematics students in multilingual classroom settings like in the case of South Africa is that of linguistic alienation from the classroom discourse, because they lack fluency and proficiency in the language of teaching and learning, students are particularly disadvantaged with respect to their ability to listen with understanding, to comprehend the written word, to express themselves orally and in writing, and to develop conceptual understanding of 
the mathematical concepts and procedures. In the early years of schooling, a discontinuity between students' dominant language or mother tongue and the language of teaching and learning usually transforms into a mismatch between the students' background knowledge and the new content being presented in school (Tavil, 2009).

Kleemans et al's (2011) position paper on education in multilingual contexts argues for the need to strike a balance between, allowing students easy task because of a number of factors, including the complexity of the linguistic and ethnic landscape in many schools, lack of concrete measures to implement the official language-in-education (LiE) policy, limited or unavailability of mother tongue instructional materials, and negative attitudes towards the use and development of mother tongues. Again, one of the challenges encountered by mathematics students in multilingual classroom settings like in the case of South Africa is that of linguistic alienation from the classroom discourse, because they lack fluency and proficiency in the language of teaching and learning, students are particularly disadvantaged with respect to their ability to listen with understanding, to comprehend the written word, to express themselves orally and in writing (Barwell, 2005), and to develop conceptual understanding of the mathematical concepts and procedures because majority of them majority of learners learn mathematics in English, which is the language of assessment and second or foreign language to most learners this has been an issue of great concern among mathematics educators (Barwell,2006) and they have suggested a lot of factors contributing to abysmal achievement in mathematics among second language learners.. Previous review of studies in South Africa have shown a contradictory and controversial findings, that dominant language or mother tongue and the language of teaching and learning usually transforms into a mismatch between the students' background knowledge and the new content being presented in school (Durkin and Shire 1991).

Kleemans et al's (2011) position paper on education in multilingual contexts argues for the need to strike a balance between, allowing students to use their mother tongues as cognitive tools in the classroom and providing them access to global languages of communication through education so that they can successfully compete nationally and globally. Some have suggested the use of learners home language as a resource in mathematics classroom with the use of techniques such as code-switching, translation, re-voice, etc.). Also, the use of English in teaching mathematics has been criticised as been a vehicle of acculturation and a trait for maintaining privilege (Barwell, 2006). Contrary to this in the paper presented by Howie (2004) on the analysis of large scale study of South Africa learners in the Third International Mathematics and Science Study of 1995. (TIMSS) she identified the learners' proficiency in English as a strong predictor of their success in algebra which is an important aspect of mathematics while home language has no significant effect on students achievement.

Again, the aspect of mathematics that is language dependent is algebra word problem which is the springboard for problem solving in algebra, in which mathematical problems have to be extracted from a meaningful context. Algebra is one of the oldest aspect of mathematics and a major focus of mathematics curriculum; studies have indicated that success in algebra is important in careers outside of academia. Kaplan et al (2009) state that algebra often serves as a gate keeper to success in high school, post-secondary education, and many career paths. However, its learning has remained a significant challenge to students all over the world; there are three fundamental understanding in learning algebra which can serve as impediment to mastering it by many students, the abstract reasoning, the language and the structure. However, Blume and Heckman, (2000) state that students' performance in algebra is particularly worrisome, there have been a great deal of work directed at understanding students difficulties in algebra teaching and learning but there is no clear evidence that the researches have had a significant effect in terms of improving attainment. Indeed, the teaching and learning of algebra continue to be a major policy concern around the world. Again, algebra teaching in South Africa schools focuses on manipulative skills of simplifying, factorising, solving equation, functions and graph, variables, word problems and patterns. It is introduced to pupils in South Africa around the ages of 13 and 14years, debates on the place of algebra in mathematics curriculum has been ongoing especially in a linguistically and ethnically diverse classroom like South Africa, multitude of studies have acknowledged the effects of lexically ambiguous language on the construction and communication of accurate concepts. (Rutherford, 2000; Kaplan et.al; 2009).

Many anecdotal reports have revealed pupils misinterpretation of algebraic expressions in an attempt to decode ambiguity in its everyday sense. (Barwell, 2005) states that lexical ambiguity does not always provide clarity learners need in order to make sense of algebra problem. Also, (Schleppegrell,2007) notes that ambiguity create difficulty in mathematical communication these are indications of the difficulties encountered in classroom teaching and learning and low achievement in mathematics among second language learners. Some of the findings are not within the scope of this study. This study is on the impact of language difficulty in algebra on students' academic performance; some studies have also looked into other factors related to mathematics achievement in its general sense ranging from motivation, personality characteristics gender, race and home-language (Kaplan et al 2009, Kara, 2009, and Howie 2004). 


\subsection{Algebra: A fundamental aspect of mathematics curriculum}

Algebra is a fundamental aspect of mathematics curriculum which involves substitution, factorisation and problem solving and drawing of graphs. It forms a large component of the mathematics curriculum for high school and for further study in mathematics related courses. It is often the first course in which students are exposed to abstract reasoning and problem solving (Perry 2002).Studies have revealed that the abstract nature of algebra increase its difficulty (Howie, 2005). Algebra involves both concrete or procedural level and abstract reasoning. It is an aspect of mathematics dealing with symbolizing and generalizing relationships and mathematical structures, and operating within those structures (Kleemans et al, 2011 p.391) Again, they point out that algebra is one of the most frightening branches of school mathematics, In the recent time, the final report of the National Mathematical Advisory Panel (2008) indicate that American students are struggling with many aspects of mathematics, the panel sees "algebra as a central concern" The learning of algebra is difficult and it has been suggested that a progressive introduction to algebra in the early grades may facilitate students' understanding

Lager (2006) says a large proportion of study into problem-solving in algebra is situated in the area of word problem; this is the springboard for which the study of algebra is situated in the contexts and content. Word problem can be seen as a connection between literacy and numeracy because it contains more information expressed in words than other numerically inclined aspects of mathematics. It is also known as "story problem' There have been a lot of debates on word problem on scholarly studies for many years and studies have viewed it from different angles and established that verification, confidence, field independence, and self-esteem are some of the factors that contribute to high levels of success in mathematical problem solving .Other debates have focused on linguistic issues and some of the key variables that have been explored include: semantic structure, clarity of word order of the problem together with the language of the test items.

Howie (2004) says the mathematical proficiency and language background of the learners. A large body of literature have established that students perform poorly in algebra word problem as compared to straight computation task. Barwell (2005). argue that some of the difficulties students experienced that led to poor performance are related to reading comprehension, syntactic variables the presence of "cue" words or the size of numbers involved However, recent studies have challenged this notion Kaplan et al (2009) suggest that with certain simple kind of algebra word problem, high school students and college students "were better" at solving simple story problems than the analogous equations.

Again, the importance of algebra in the classroom pedagogy not withstanding there are many problems in the teaching and learning of the domain. Blume and Heckman, (2000) suggest that many students see algebra as the area where mathematics abruptly becomes a non-understandable world. This has been the notion in 1982; the Cockcroft Report in the UK identified algebra as a source of substantial confusion and negative attitudes among students. They argued that many students consider algebra as an unpleasant, alienating experience and find it difficult to understand. The Chief Examiner's reports $(1999,2003$, and 2006) have considered algebra as an area of flaw in national examinations over the past number of years the report showed that there has been little or no progress at all in students' performance in the past ten years. This is an indication that the pride of place algebra enjoyed in mathematics curriculum notwithstanding students still has challenges in comprehending and applying even its basic concepts.

The national evaluation is evidence on the urgency on this issue of poor performance in a data collected in 2007, the majority of Grade 6 teachers in South Africa cannot answer a question that their learners ought to be able to answer based on the Grade 6 curriculum. In one example, 'only 23 per cent of South African Grade 6 mathematics teachers could answer (such a Grade 6) The table below shows the circulation of results of 2012 Annual National Assessments (internationally benchmarked national tests) for Grade 9 Mathematics.9 There are issues around the reliability of these tests, but it is obvious that less than 5 per cent of learners achieved 40 per cent or more in mathematics.

Table 1: 2012 Grade 9 Mathematics Scores by Percentage Range

\begin{tabular}{|l|c|}
\hline Range & Percentage of Scores \\
\hline Less than 30\% & 91,9 \\
\hline $30-39 \%$ & 3,8 \\
\hline $40-49 \%$ & 2,1 \\
\hline $50-59 \%$ & 1,1 \\
\hline $60-69 \%$ & 0,6 \\
\hline $70-79 \%$ & 0,3 \\
\hline 80 and over & 0,2 \\
\hline Total & 100 \\
\hline
\end{tabular}

Source: Report for CDE, performance in South African Educational System 


\subsection{Rationale for this study}

From the aforementioned background, it is evidence that there has been an abysmal performance of learner in algebra. It is therefore pertinent to explore some of these ambiguities in algebra that culminating to the poor performance in algebra as an aspect of mathematics South Africa. Hence, this study investigates and reveals these ambiguities in algebra as an aspect of mathematics. Model for conceptualizing algebraic activity was also discussed.

\subsection{Model for conceptualizing algebraic activity}

Lager (2006) establishes a model for conjecturing algebraic activity in which he recognized three main constituents of school algebra: namely,

- Generational activities: These are activities where students generate their own rules, expressions or equations from given situations.

- Transformational activities: These are often referred to as rule-based activities and entail an appreciation of the need to follow a well-defined rules and procedures.

- Global/meta-level activities: These activities is applicable to all of mathematics and are not limited to algebra, e.g. finding the mathematical structure underlying a situation ,being heedful of the limitations of a problem situation, and explaining and justifying.

Lager's model recommends that teachers must place emphasis on all activity when teaching school algebra. The aim of Lager's model is to strike a balance between algebraic activities arguing that all activities are important and that teachers need to address all. There must be a paradigm shift from the traditional way to the contemporary approach of teaching both the techniques and conceptual understanding without circumventing the symbol manipulation and rulebased procedures. He also stressed that students must be made to understand the purpose of what they are learning which will serve as propelling force and the consciousness of mathematics constraints and structure must also be noted.

\section{Lexical Ambiguity: The Challenges of Algebra}

Studies have indicated that the abstract nature of algebra is one of the causes of challenges students face in its study and that the abstract nature increases its difficulty over arithmetic (Howie, 2004), because algebra is often the first course in which students are asked to engage in abstract reasoning and problem solving. Students who have been exposed to mathematics at a procedural level, typical in many classrooms will have to bridge the difficult gap from concrete to abstract reasoning with no preparation. This inexperience with abstractness for the construction of meaning directly hinders the ability of students to accomplish multiple representations of algebraic objects. Secondly, the learning of algebra expects students to learn a language of mathematical symbols that is also completely foreign to their previous experiences.

The different ways in which the language is labelled and used during instruction often prevent students from connecting algebraic symbols to their intended meaning (Lager, 2006). At times , students are completely oblivious of any meaning that was intended for the symbols while at other times they, may know that meaning exists, but inadequate understanding will prevent them from assigning meaning to the symbols, or they may give erroneous meaning to the symbols (Howie, 2004). For example, as students study topics such as functions and graphs, they begin to understand and interpret one set of algebraic objects in terms of another (e.g., a function equation with its graph, a data set by its equation, a data set by its graph, Kaplan et al (2009) find that students are generally able to plot points and equations; however, in spite of this procedural fluency, students lack the ability to extract meaning from graphical representations whereas both the procedural and graphical representation must go hand in hand.

Specifically, students are readily capable of demonstrating procedural fluency, but memory and procedural understanding is unable to guide students through problems involving interpretation it was also found out that learning the structural characteristics of algebra creates a third challenge for students. For example, students often fail to identify the differences between expressions and equations. They also have difficulty hypothesizing an equation as a single object rather than a collection of object and meaning of equality is often confused within algebra contexts at the same time from the ongoing it shows that structural challenges often prevent students from recognizing the utility of algebra for generalizing numerical relationships. Therefore, the three initial understandings, abstract reasoning, language acquisition, and mathematical structure, are often the major impediments to students in algebra classroom. The initial impression students have usually contributed in a great way to their challenges in algebra at different stages.

Again, the teaching methods used to deliver content often aggravate these algebra learning barriers, even 
becoming a unique barrier themselves (Perry, 2000). The difficulties of achieving competence in abstract reasoning, language acquisition, and mathematical structure within the learning of algebra require teaching approaches that tenaciously target the needs of learners. For example, in recognition of the difficulties some students have been learning algebra in isolation, cooperative and collaborative learning offers a relevant pedagogical option. For students struggling to connect abstract concepts with concrete examples, mastery learning and problem-based learning may be an appropriate strategy or alternative.

\subsection{Word Problem in Algebra}

Mathematics instructional perspectives relevant to students' lives and experiences have been researched widely both locally and internationally. (Perry, 2000, Kara, 2009, and Howie 2004). In the field of mathematics education, story problems, or word problems, have been widely researched as a way of contextualization, which is not unanticipated given that they form a large part of school curriculum, instruction, and assessment from kindergarten to undergraduate mathematics course. A current national survey of 743 Algebra teachers compiled for the National Mathematics Advisory Panel showed that "solving word problems "was cited as the most serious setback for incoming students. This indicated that issues surrounding story problems of major concern to mathematics educators today, algebra. Also, algebra word problem involves a narrative or story; it is also referred to as story problems. (Tobogo, 2013), algebraic word problem usually consists of one or more sentences having some known or unknown principles with underlying algebraic equations.

The problems present a situation or a story which requires understanding components that make up the problem in order to generate a mathematical notation to represent it. The notation consists of one or more equations; and solving the equations will yields numerical values that solve the problem. When a problem is presented as a text rather than in mathematical notation it becomes a word problem. Again, algebra is principally 'a systematic way of expressing generality and abstraction' (Kaplan, et.al; 2009, p.156) It also involves representation through translation of verbal information into symbolic expression and equations, the focus is on representation of relations. Algebra word problem is an essential part of mathematics education because it is an aspect of mathematics pedagogy . However, traditionally word problems have been difficult for many people, studies from a discourse perspective, have shown that most of the difficulty with word problems arises from a disparity between text comprehension, situation comprehension, and problem solving procedures. This difficulty becomes complex by the nature of the problems' text. Ample explanations have been given from past studies to analyse how the wording of arithmetic story-problems influences performance

\subsection{Fallacies and Hitches of Word Problem in Algebra}

Past studies have examined the misconceptions students have regarding algebra word problems and pointed out that the translation stage is the source of most of the misconceptions. Students have difficulty "recognizing the mathematical or cognitive demand, and understanding the problem in its context" It was noted that students who lack the linguistic knowledge required to comprehend the demands of the math problem have particular difficulty. Despite the fact that students do comprehend the basic operations and can manipulate equations, they still have problems in creating the equations and understanding what they have to do and why they are doing it. Tebogo (2013) argues that the ability to take a problem situation and formulate a mathematical notation is the most vital skill needed to succeed in algebra problem solving. "Even if a student has access to a spreadsheet or graphing calculator, the student will still need to be able to translate a problem into the language of mathematics (i.e., an algebraic expression)". This means that procedural ability coupled with conceptual ability are needed for success in algebra word problem

Schweinle et al (2006) conducted research with 244 college students and 81 7th graders to observe them solving algebraic word problems. They found that nearly all of them were able to solve simple problems, such as ones with a single schema1 in it, indicating basic understanding of algebraic concepts. However, the students experienced progressively greater difficulty as the complexity of the problems or the number of steps to reach the solution increased. They concluded that even among college students there is great difficulty in solving complex, multistep algebra problems. They also believe that the nature of the difficulties demonstrated by the participants in their experiments is related to misconceptions in comprehension of multiple relational schemas to create problem representations. In own their opinion, metacognitive knowledge is what enables some students (and not others) to build complex representations and devise solutions for difficult problems. 


\subsection{Linguistic complexity in Algebra}

Language is an essential element of teaching and learning of algebra because it facilitates mathematical knowledge transmission. (Panel and Bal. 2003.p.1) describes language as "a unified system of meaning-making" that integrates the multiple semiotic resources of natural language, technical mathematics terminology (register), and non-linguistic symbol and visual forms of representation. In order to solve mathematical problem, language play a vital role if the language is complex it will be difficult for students to decode or interpreted the symbolic forms and it will compromise students' understanding of word problem. The linguistic features of natural language that create comprehension difficulties for English Language Learners (ELLS) include vocabulary, lexical complexity/ambiguity. Again, language difficulty can be referred to as language complexity and in the context of this study it is equally referred to as lexical ambiguity. In the past few decades, empirical studies have shown the relationship between some linguistic features and the difficulty of algebra word problem for ELLs and non-ELLs in elementary, middle and high school levels (Adetula 1990). Even though, many of these studies predicted a relationship between linguistic complexity and Ells' performance in mathematics word problems, the effect of specific linguistic features varied from test to test and from on grade to another. Many studies that have identified language as a source of differential performance between ELL and non-ELLs have attributed difficulty to students understanding of the written text rather than student's ability in mathematics.

The difficulty of language used in mathematics items is posited to have a disproportionate impact on English Language Learners (ELLS) due to their low language proficiency or general language skills. In South Africa, students' achievement in mathematics is affected by linguistic complexity because mathematics is taught and learned in a second language in schools both in the rural and urban centre (Kleemans et al, 2011). Also some of the challenges students face is associated with the technical vocabulary of mathematics which includes the following.

1. The use of technical words or discrete set of mathematical terminology that are not usually used by students outside mathematics classroom Examples might include 'parallelogram' and 'multiplication'. Because they are not used in everyday meaning student do perceive that they are not related to life outside school.

2. There are many words that are used in everyday English, which have diverse or much more specific meanings in mathematics. For example, in relation to subtraction the 'difference between 8 and 13' is not that one has one digit and the other has two digits. Other familiar examples would include: 'volume' (in everyday English used mainly for levels of sound); and 'right' as used in 'right angle' (not the opposite of a left angle!). Mathematics uses 'odd' to refer to every other counting number, which is hardly consistent with the everyday usage of the word.

3. Words in mathematics are naturally used with specific meanings. But in ordinary everyday English, many mathematical words are misused or used with a degree of sloppiness, which can be a barrier to pupils' understanding of mathematical concepts. 'Sugar cubes' are usually cuboids, but not all of them are actually cubes. Adults do not mean a time interval of one second when they say, 'Just a second!' The phrase 'a fraction of the cost' uses the word 'fraction' imprecisely to mean 'a small part of'. And the word 'half' is often used to mean one of two parts not necessarily equal.

\subsection{Proficiency in the Language of Instruction}

Language of learning and teaching can also be referred to "language of instruction" or "medium of instruction" In recent times, there has been an increasing awareness of the relevance of language in mathematics pedagogy showing that mathematics is not devoid of language but it is language-based. Durkin and Shire (1991) stated that language is an integral part of science education a means of doing science and of constructing scientific understanding. Studies have revealed that there is a close link between proficiency in the language of instruction and students' understanding of mathematics, language proficiency is therefore related to learning ability and general academic achievement (Brokes and Etkina, 2007) As a result of this phenomenon of language and mathematics many students are now learning mathematics in their second or third language and this is making English to become the language of instruction and lingua franca at this era of globalization. Mathematics meaning is achieved through language. The language of instruction may be a barrier rather than a tool for communication and may contribute to low levels of mathematics achievement.

Studies have shown that language is one of the stumbling blocks for mathematics understanding, especially for students learning mathematics in their second or third language, mathematics is not "language free "and due to its particular vocabulary, syntax and discourse it can cause problems for students learning it in their second language at all levels of education. (Fakeye, 2010) also points out that by importing theories from linguistics, there is a danger of misreading and simplifying, and she states that there is a difficulty in agreeing what is meant by 'language'. He suggests 
that a certain level of linguistic proficiency seems to be in general necessary for academic achievement, but not language as such, but skills in a certain type of language.

\section{Conclusion and Recommendations}

This study has revealed some of the lexical ambiguities in algebra aspect of mathematics. These ambiguities include among others; word problem in algebra, fallacies and hitches of word problem in algebra, linguistic complexity in algebra, proficiency in language of instruction problem just to mention but a few. Studies have shown that the inability of the teachers to possess language proficiency has bedevilled the performance of students in mathematics especially algebra where language of teaching is very essential. There should be a paradigm shift in the method of teaching algebra and mathematics as a subject so as to enhance students' academic performance. The choice of methodology especially the student-centred methods (contemporary methods of teaching) are very pertinent at this stage. Researches have shown that many students have phobia for mathematics (Adu, 2012, Barwell 2005, and Bernado 1990). Hence, there is need for teachers to update their knowledge about the problem solving skills that can be used as a panacea to mathematics phobia.

\section{References}

Adetula, L.O. (1990). Language Factors Does it affects children's Performance on word problem? Education Studies in Mathematics, 21,351-365

Adu, E.O (2012) Two Problem Based Learning Strategies for Teaching Economics. An Action Research Paradigm Shift. Lambert Academic Publication. Germany.

Barwell, R (2005) 'Ambiguity in the Mathematics classroom Language and Education 19(2), 118-126

Barwell, R (2006). Patterns of attention in the interaction of a primary school Mathematics student with English as an additional Language. Educational Studies in Mathematics (1), 35-59

Bernado, A.B.I, (1990) Overcoming obstacles to understanding and solving word problems in mathematics. Educational Psychology 19,149

Blume, G.W \& Heckman, D.S (2000). Algebra \& Functions in E.A Silver and P.A Kenney (Ends)

Bouchey, H, A and Harter, S (2005) Reflected appraisals, academic, self- perceptions, and mathematics/science performance during early adolescence. Journal of Educational Psychology. 97:673-686.

Brokes, D.T and Etkina, E (2007).Using conceptual metaphor and functional grammar to explore how language used in Physics affects student learning. APS Journal.Phys.Rev, ST Physics Ed. Research vol. 3, issue1

Daniel, J. \& James. (2003) A. Relationship between students and Instructional Factors in Algebra. Achievement of students in United States \& Japan: An Analysis of TIMSS 2003 Data

Department of Basic Education (2011). Curriculum and Assessment Policy Statement. Grades 10-12 (General) mathematics. Pretoria: Department of Basic Education.

Durkin, K \&Shire, B (1991) Lexical Ambiguity in Mathematical Contexts. In K.Durkin \& B.Shire (Ends), Language in Mathematical Education: Research and practice (pp.71-84). Philadelphia: Open University Press.

Department of Education (2000): Norms and standards for Educators. Pretoria.

Fakeye, D (2010) Students' Personal Variables as Correlates of Academic Achievement in English as second Language in Nigeria. Journal of Social Sciences, 22(3), 205-211.

Forster, P.A and Taylor P.C (2003) "An investigation of communicative Competence in an upper-secondary class where using calculator was a routine," Educational Studies in Mathematics 52 (1), 57-77

Howie, S.J (2004) A national assessment in Mathematics within International Comparative Assessment Perspective in Education 22,149-162.

Kaplan, Fisher, and D.G \& Rogness, N.T (2009) Lexical ambiguity in Statistics: What do students know about words association? Average, confidence, random and spread? Journal of statistic Education.

Kara, A (2009) The Effects of a Learning Theory unit of students' Attitudes towards Learning. Astralian Journal of Teacher Education, 34(3), 100-113.

Kleemans, T, Segers, E, Verhoeven, L. (2011) Cognitive and linguistic Precursors to numeracy in kindergarten: Evidence from first and second language learners learning and individual Differences vol.21 issues

Lager, C.A (2006). Types of mathematics language reading Interactions that unnecessarily hinder Algebra learning and Assessment. California. Taylor Francis Group, LLC. 165-150p.

Le Febvre, J. Fast, L. Skwarchuk, S. Smith-chant, B.L. Bisanz, J. Kamawar, D. (2010), Pathway to Mathematics: Longitudinal Predictors of Performance Child Development, 81, 1753-1767.

Morgan, C. (2007). Educational Studies in Mathematics, vol. 61, no 1 219-245.

National Mathematics Advisory Panel. (2008). Foundations for Success: The final report of the National Mathematics Advisory Panel Washington DC: U.S Department of Education 
Panel, C \& BaL, D.L. (2003) Mathematical Proficiency for All students. Santa Monica CA.RAND

Perry, M. (2000). Explanations of Mathematical concepts in Japanese Chinese and United States first-and-fifth grade classrooms Cognition and Instruction. 18,181-207

Rutherford, C (2000) Integrating science, mathematics and Technology. Prentice Hall.

Schleppegrell, M (2007). The challenges of Mathematics Teaching and learning; a research review. Reading and Writing Quarterly 23; 139-159

Schweinle, A. Meyer, D.K \&Turner, J.C (2006). Striking the right balance: students" motivation and affect in elementary Mathematics. Journal of Educational Research, 99,271-293

Tabachnick, B.G \&Fidel, L.S. (2007). Using multivariate statistics. (5thEd.). Boston: allyn and Bacon.

Tavil, Z (2009).Parental Attitudes towards English Education for kindergarten Students in Turkey. Kastamonu Education. Journal. 17(1), 331-340.

Tobogo, M (2013, December 9th) Poor Grade 9 ANA results need action. The Independent Newspaper Limited. Retrieved February 26, 2014 from www.ioi.co.za/lifestyle. 